\title{
ON A FOLD SOMETIMES TO BE FOUND IN FRONT OF THE POSTERIOR NASAL OPENING.
}

\author{
By W. G. Porter, M.B., B.Sc., F.R.C.S.Ed., \\ Surgeon to the Eye, Ear, and Throat Infirmary. Filinlur,gh : Clini \\ Ear and Throat Department, Royal Infirmil'y. Filinhurght.
}

In a case of congenital unilateral atresia of the choana, which came under my observation in the poliklinik of Dr. Max Scheier, of Berlin, and of which an account has been published elsewhere (1), my attention was drawn to a fold which was present on the unobstructed side. The appearances (vide Fig. 1) as seen on posterior rhinoscopy may be here quoted: "On the roof immediately in front of the posterior nasal opening a narrow grey strip of tissue is visible, apparently an attempt at the formation of an occluding membrane on this side also. This felt hard when tonched with a probe."

A fold resembling this was subsequently observed in a number of persons who were apparently healthy; no reference to this could be found in any literature to which access was obtained, with one possible exception (vide infra), and it therefore seemed fitting to make this the subject of a clinical and anatomical investigation.

On clinical examination the fold is to be found on an average in one person out of three, assuming one of three forms: (1) When most marked it extends on to the septum running parallel to and slightly in front of its posterior margin; it passes from the septum on to the roof, ceasing just above the posterior end of the middle turbinated body. (2) It may be well marked on the roof, passing out towards the middle turbinated body, but not extending on to the septum. (3) It may appear as a very narrow strip limited to the roof. The fold is characterised in every case by its greyishwhite colour.

The anatomical part of the investigation was carried out partly in the anatomical department of the University of Berlin and partly in the anatomy rooms of the University of Edinburgh, in the former by the kind permission of Professor Waldeyer and in the latter by the courtesy of Professor Cunningham. I therefore take this opportunity of expressing to them my hearty thanks and indebtedness.

In all, forty-one skulls of adults were examined. In Berlin only the "parts" in the dissecting-rooms were inspected. At this stage of the dissection the skull is divided in the sagittal plane, the nasal septum being left on one half, which half alone was made use of ; 
this precaution and the fact that the "parts" are numbered obviated the risk of any part being noted more than once. In Edinburgh the specimens in Professor Cunningham's collection were examined, and as these are of course labelled and only a few dissecting-room "parts" were handled in the investigation, no possibility arose of any part being noted twice.

In the forty-one specimens under notice the fold was found in 17 , or 41 per cent.; when present it is situated from 5 to $10 \mathrm{~mm}$. in front of the posterior nasal opening. In its least marked form it is confined to the under surface of the body of the sphenoid, in its most marked forms it extends inwards half way or more down the septum, and outwards towards the posterior end of the middle turbinated body on to the inner aspect of the internal pterygoid plate (see Fig. 2). In the fold a ridge of bone can occasionally be felt. A number of macerated skulls were inspected, but no ridge was seen in this position in any one of them.

To prevent confusion it was found advisable soon after the investigation was commenced to note the relations of the fold, which marks the position of the choana itself. This was done in thirty cases. It extends from the posterior margin of the septum upwards and outwards on the under aspect of the body of the sphenoid and ends in one of three ways. Usually, in nineteen, it was found to blend with the anterior lip of the Eustachian cushion, in seven it reached the middle of the upper margin of the Eustachian cushion, while in four it was lost above that point.

In addition to the skulls of adults, eight skulls of full-time fotus were inspected; three of these showed a second fold (vide Fig. 3) similar to that described above.

Having thus established the existence of this fold, the question arises, What is its significance? We might naturally suppose that it is merely the result of some pathological process. This supposition is, however, negatived by the fact that the fold is frequently to be found on rhinoscopic examination of healthy people, and further by the fact that the appearances in the different specimens are so similar. These same facts exclude the possibility of this structure being due to post-mortem changes.

Now, when the fold was seen for the first time in conjunction with a unilateral atresia of the choana, the idea at once suggested itself that we had to deal here also with a partial occlusion of the choana, presumably of a nature similar to that on the completel! obstructed side. 
Table showing Results of Exxminations of Forty-one Adult and Eight Fotal Skulls.

\begin{tabular}{|c|c|c|c|}
\hline Skull No. & Second fold. & $\begin{array}{c}\text { Distance in front of } \\
\text { choana in mm. }\end{array}$ & Choanal fold. \\
\hline 1 & 1 & 8 & Not examined \\
\hline 2 & 0 & - & ", $\quad$, \\
\hline 3 & 0 & - & , , , \\
\hline 4 & 3 & 7 & " $\quad "$ \\
\hline 5 & 2 & 3 & 3 \\
\hline 6 & 0 & - & 2 \\
\hline 7 & 0 & - & Not examined \\
\hline 8 & 0 & - & " $\quad "$ \\
\hline 9 & 0 & - & 2 \\
\hline 10 & 0 & $\overline{10}$ & Not examined \\
\hline $\begin{array}{l}11 \\
12\end{array}$ & 2 & 10 & 1 \\
\hline $\begin{array}{l}12 \\
13\end{array}$ & $\begin{array}{l}1 \\
0\end{array}$ & 6 & $\begin{array}{c}2 \\
\text { Not examined }\end{array}$ \\
\hline $\begin{array}{l}13 \\
14\end{array}$ & $\begin{array}{l}0 \\
2\end{array}$ & $\overline{4}$ & Not examined \\
\hline 15 & 0 & - & $"$ \\
\hline 16 & 1 & 8 & 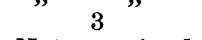 \\
\hline 17 & 0 & - & Not examined \\
\hline 18 & 1 & 8 & 2 \\
\hline 19 & 0 & - & 1 \\
\hline 20 & 1 & 6 & 1 \\
\hline 21 & 0 & -- & 1 \\
\hline 22 & 0 & - & 1 \\
\hline 23 & 0 & - & 1 \\
\hline 24 & 0 & - & 1 \\
\hline 25 & 1 & - & 1 \\
\hline 26 & 0 & - & 1 \\
\hline 27 & 1 & 7 & 1 \\
\hline 28 & 0 & - & 1 \\
\hline 29 & 0 & - & 1 \\
\hline 30 & 0 & - & 3 \\
\hline 31 & 0 & - & 3 \\
\hline 32 & 2 & 5 & 1 \\
\hline 33 & 0 & - & 1 \\
\hline 34 & 0 & - & 2 \\
\hline 35 & 1 & 5 & 1 \\
\hline 36 (Hd. I) & 3 & 4 & 1 \\
\hline 37 (B8) & 0 & - & 1 \\
\hline 38 (Hd. III) & 0 & 一 & 1 \\
\hline 39 (Hd.notnumbered) & 1 & 6 & 2 \\
\hline 40 (organ sense series) & 3 & 6 & 2 \\
\hline 41 & 3 & - & 1 \\
\hline \multicolumn{4}{|c|}{ Foetal Skulls. } \\
\hline 1 & 0 & $1-$ & 3 \\
\hline 2 & 2 & 2 & 3 \\
\hline 3 & 0 & - & 3 \\
\hline 4 & 0 & - & 1 \\
\hline 5 & 0 & - & 1 \\
\hline 6 & 2 & - & Not examined \\
\hline 7 & 0 & - & ", $\quad$, \\
\hline 8 & 1 & 3 & 一 \\
\hline
\end{tabular}

Explanation of table.-In the second column the figure 1 denotes that the fold passed on to the septum and out to the middle turbinated body; the figure 2 denotes that the fold passed out to the middle turbinated body but not on to the septum. and the figure 3 means that the fold was restricted to the roof. In the fourth column the figure 1 means that the choanal fold blended with the anterior lip of the Eustachian cushion, the figure 2 that the fold joined the middle of the upper border of the Eustachian cushion, and the figure 3 that the fold was lost above this point. The first 32 skulls were examined in Berlin, the remainder in Edinburgh. 
Hochstetter (2) has shown in a paper on the development of the primitive choana that the nasal cavity is formed by the union from behind forwards of the epithelial covering of the lateral and mesial nasal processes, and that the nasal cavities are separated from the mouth and pharynx from the earliest stages of their development. The floor of the nose is thickened by the ingrowth of mesoderm from both lateral nasal processes, while the most posterior part remains as an epithelial layer and is thinned out by the increase in size of the nasal cavity, thus forming the bucco-nasal membrane. This finally gives way and then the primitive choana is formed.

These observations have been confirmed by Tiemann (3) and Keibel (4).

Haag (5) was the first to suggest that a persistence of this bucconasal membrane might be the cause of the atresia of the choana; if this is so it is only to be expected that lesser degrees of the condition should be found. Now, it is well knowu that choanal atresia is sometimes incomplete, moreover the obstruction varies also in structure, consisting sometimes of bone and at other times of membrane, or, again, being formed partly of the one and partly of the other.

All these facts seem to support the view that this small fold has the same origin as congenital atresia of the choana, while the greater frequency of the appearance of the former may sufficiently be explained by the very minor degree of its development.

The only reference which I could find in any literature to a fold such as this was in a paper by Hopmann (6), who says that single folds are to be found rarely in the region of the upper or lower boundary of the choana, but that when existing they do not appear to be the result of an ulcerative process, but rather dne to an irregularity in development of a congenital nature. Bergeat (7), however, referring to Hopmann's paper, found no such remarkable appearances.

The conclusions which, I think, may be drawn legitimately from this study are the following:

(1) That a fold is sometimes present on the roof of the nose slightly in front of the choana.

(2) That this fold is a vestigial structure, being the remains of what was once the bucco-nasal membrane, and, moreover, that a persistence of the whole of the bucco-nasal membrane results in the production of the condition known as congenital atresia of the choana. 


\title{
References.
}

(1) Porter.-Edin. Med. Journ., February, 1906.

(2) Hochstetrer.-Verhand. d. Anat. Gesellschaft, 1891.

(3) Tremann.- “ Über die Bildung der primitiven Choanen bei Säugethieren,” Wurzburg, 1896.

(4) Kribel.-Anatom. Anzeig., vol. viii, 1893.

(5) HAAG.-Archiv f. Laryngol. u. Rhinol., Bd. ix.

(6) Hopmann.-Archivf. Laryngol. u. Rhinol., Bd. iii.

(7) Bergeat.-Archiv f. Laryngol. u. Rhinol., Bd. iv.

\section{SOCIETIES' PROCEEDINGS.}

\section{PROCEEDINGS OF THE OTOLOGICAL SOCIETY OF THE UNITED KINGDOM.}

\author{
Twenty-eighth Ordinary Meeting, held at the Medical Society's Rooms, 11, Chandos \\ Street, W., on Monday, December 3, 1906.
}

The President, A. E. Cumberbatch, F.R.C.S., in the Chair.

Report of the Pathological Commitee.

The Pathological Committee of the Otological Society met on November 12, to examine and report on the following microscopical specimens :

(1) Mr. Yearsley's "Ulcer of the Auricle," vide Transactions, vol. vii, p. 17.

(2) Mr. H. E. Jones' “Tumour of the Pinna," vide Transactions, vol. vii, p. 50 .

\section{RePoRt.}

(1) The bulk of evidence is in favour of this being an epithelioma, but no mitoses are to be seen, which if present would confirm this opinion.

(2) Is an angeioma, consisting of both blood- and lymph-vessels.

Arthur H. Cheatle.

Wratt Wingrave.

C. H. Fagge.

The following communications were made : 